\title{
Stem cell mobilization chemotherapy with gemcitabine is effective and safe in myeloma patients with bortezomib induced neurotoxicity.
}

\begin{tabular}{|r|l|}
\hline Journal: & Leukemia and Lymphoma \\
\hline Manuscript ID: & GLAL-2015-0435.R1 \\
\hline Manuscript Type: & Original Article - Clinical \\
\hline Date Submitted by the Author: & $\mathrm{n} / \mathrm{a}$ \\
\hline Complete List of Authors: & $\begin{array}{l}\text { Pabst, I homas; Bern University Hospital, Department of Medical Oncology } \\
\text { Mueller, Beatrice; University of Bern, Department of Clinical Research } \\
\text { Kcllcr, Sandra; Univcrsity Hospital Bcrn, Dcpartmcnt of Mcdical Oncology } \\
\text { Seipel, Katja; University of Bern, Department of Clinical Research } \\
\text { Mansouri Taleghani, Behrouz; University Hospital Bern, Department of } \\
\text { Hematology } \\
\text { Rauch, Daniel; Kantonsspital, Department of Medical Oncology } \\
\text { Betticher, Daniel; Kantonsspital, Department of Medical Oncology } \\
\text { Egger, Thomas; Kantonsspital, Department of Medical Oncology }\end{array}$ \\
\hline Keywords: & $\begin{array}{l}\text { Stem cell mobilization < Marrow and Stem Cell Transpantation, Myeloma < } \\
\text { Neoplasia, Clinical Results < Marrow and Stem Cell Transpantation }\end{array}$ \\
\hline \hline
\end{tabular}




\title{
Stem cell mobilization chemotherapy with gemcitabine is effective and safe in myeloma patients with bortezomib induced neurotoxicity.
}

\begin{abstract}
AUTHORS: ${ }^{1}$ Beatrice U. Mueller, ${ }^{2}$ Sandra Keller, ${ }^{1}$ Katja Seipel, ${ }^{3}$ Behrouz Mansouri Taleghani, ${ }^{4}$ Daniel Rauch, ${ }^{5}$ Daniel Betticher, ${ }^{6}$ Thomas Egger, ${ }^{2}$ Thomas Pabst.

AFFILIATIONS: ${ }^{1}$ Department of Clinical Research, University of Berne; Berne, Switzerland; ${ }^{2}$ Department of Medical Oncology, University Hospital of Berne; Berne, Switzerland; ${ }^{3}$ Department of Hematology, University Hospital of Berne; Berne, Switzerland; ${ }^{4}$ Department of Oncology; Kantonsspital; Thun, Switzerland; ${ }^{5}$ Department of Oncology; Kantonsspital; Fribourg, Switzerland; and ${ }^{6}$ Department of Oncology; Kantonsspital; Solothurn, Switzerland.
\end{abstract}

RUNNING HEAD: Gemcitabine for mobilization in myeloma.

\begin{abstract}
ABBREVIATIONS: MM: multiple myeloma; HDCT: high-dose chemotherapy; ASCT: autologous stem cell transplantation; G-CSF: granulocyte-colony stimulating factor; PN: peripheral neuropathy; CIPN: chemotherapy-induced peripheral neuropathy; BIPN: bortezomib-induced peripheral neuropathy; OS: overall survival; PFS: progression-free survival.
\end{abstract}

MANUSCRIPT DETAILS: abstract: 199 words (200 allowed); manuscript word count: 2832 words (3'000 allowed); 4 tables; 1 figure; no supplemental material; 27 references.

CORRESPONDING AUTHOR: Thomas Pabst MD; Associate Professor; Department of Medical Oncology; University Hospital; Berne; Switzerland. Phone: ++41 31632 8430; fax: ++4131632 3410; Email: thomas.pabst@insel.ch. 


\section{SUMMARY}

Background: Vinorelbine chemotherapy with G-CSF stimulation is a widely applied nonmyelosuppressive mobilization regimen in Switzerland for myeloma patients, but its neurotoxic potential limits its use in patients with bortezomib induced polyneuropathy.

Methods: In this single-center study, we alternatively evaluated safety and effectiveness of gemcitabine chemotherapy with G-CSF for mobilization of autologous stem cells.

Results: Between 03/2012 and 02/2013, all bortezomib pretreated myeloma patients planned to undergo first-line high-dose melphalan chemotherapy received a single dose of $1250 \mathrm{mg} / \mathrm{m} 2$ gemcitabine, with G-CSF started on day four. The 24 patients in this study have received a median of four cycles of bortezomib-dexamethason based induction. Bortezomibcaused polyneuropathy was identified in 21 patients $(88 \%)$ by clinical evaluation and a standardized questionnaire. Administration of gemcitabine mobilization did not induce novel or aggravate preexisting neuropathy. Stem cell mobilization was successful in all 24 patients, with a single day of apheresis being sufficient in 19 patients $(78 \%)$. The median yield was $9.51 \times 10^{6} \mathrm{CD} 34+$ cells $/ \mathrm{kg}$. Stem collection could be accomplished at day 8 in $67 \%$.

Conclusion: Our data suggest that single-dose gemcitabine together with G-CSF is an effective mobilization regimen in myeloma patients and a safe alternative nonmyelosuppressive mobilization chemotherapy for myeloma patients with bortezomib induced polyneuropathy.

KEY WORDS: mobilization; stem cells; myeloma; polyneuropathy; gemcitabine; bortezomib; neurotoxicity; autologous; transplant. 


\section{INTRODUCTION}

Significant advances have been reported in the treatment of myeloma patients in the last decades. The introduction of proteasome inhibitors and immunomodulatory compounds for induction treatment, high-dose chemotherapy (HDCT) followed by autologous stem cell transplantation (ASCT) for consolidation, and subsequent maintenance treatment with lenalidomide or bortezomib have increased remission and survival rates in myeloma patients (Bladé et al, 2005; Fernand et al, 2005; Giralt et al, 2011; Harrousseau et al, 2009; Ludwig et al, 2010; Rajkumar, 2011). Noteworthy, a number of studies identified an independent benefit of first-line HDCT with ASCT also in the era of novel agents, which was further enhanced by maintenance treatment after HDCT (Bladé et al, 2005; Fernand et al, 2005; Giralt et al, 2011; Harrousseau et al, 2009). These observations indicate that ASCT continues to be a component of the first-line treatment algorithm for young and fit myeloma patients (Harrousseau et al, 2009; Ludwig et al, 2010).

The optimal strategy to mobilize autologous stem cells from the bone marrow to the peripheral blood remains an issue of ongoing controversy (Giralt et al, 2011). Repetitive applications of the granulocyte colony-stimulating factor (G-CSF) alone can effectively mobilize peripheral CD34+ cells, whereas the combination of G-CSF with chemotherapy is usually associated with a more potent recruitment of CD34+ cells from the bone marrow niche. The additional administration of the expensive stem cell mobilizing compound plerixafor represents a rescue strategy for patients failing such mobilization strategies.

Based on the considerations above, the combined use of chemotherapy and G-CSF is a widely used concept. While high-dose cyclophosphamide with G-CSF is commonly given for chemotherapy mobilization, the administration of a single dose of non-myelosuppressive chemotherapy with vinorelbine $\left(35 \mathrm{mg} / \mathrm{m}^{2}\right)$ together with G-CSF started on day 4 is the standard mobilization regimen in Switzerland since more than a decade (Bargetzi et al, 2003; Heizmann et al, 2009; Samaras et al, 2015; Schmid et al, 2015). Its obvious advantages compared to cyclophosphamide treatment comprise a highly predictable stem cell collection 
at day 8 , the entirely ambulatory concept, and the lack of infectious and toxic complications notoriously following cyclophosphamide mobilization (Bargetzi et al, 2003; Heizmann et al, 2009; Samaras et al, 2015; Schmid et al, 2015).

With the predominant use of bortezomib during induction treatment and with chemotherapy-induced polyneuropathy (CIPN) as its major and often limiting side effect, the subsequent use of vinorelbine for mobilization has become increasingly problematic because of its added neurotoxicity (Argyriou et al, 2008; Carlson et al, 2011; Delforge et al, 2010; Keller et al, 2015; Koeppen et al, 2014; Mohty et al, 2010; Richardson et al, 2006; Swain et al, 2008). Clinically significant induction of novel - as well as aggravation of bortezomib induced - CIPN following mobilization treatment with a single dose of vinorelbine in myeloma patients has recently been reported by our group (Keller et al, 2015). These facts identified a need for an alternative non-neurotoxic mobilization chemotherapy, while preserving the advantages of a non-myelosuppressive strategy.

Gemcitabine has been previously used for stem cell mobilization as a part of polychemotherapy regimens in Hodgkin lymphoma patients (Suyani et al, 2011). However, its use as monochemotherapy for mobilization has not been reported so far. In this study, we investigated the safety and effectiveness of gemcitabine together with G-CSF for the mobilization of autologous stem cells in myeloma patients after bortezomib/dexamethasonebased induction treatment. 


\section{PATIENTS AND METHODS}

\section{Patients and study design}

This is a single-center prospective study analyzing all consecutive myeloma patients undergoing first-line consolidation treatment with high-dose melphalan chemotherapy (HDCT) and autologous stem cell transplantation (ASCT) between 03/2012 and 02/2013. Patients must have been treated with a bortezomib/dexamethasone-based induction regimen, the age neded to be below 71 years, and a minimum renal function with a kreatinin clearance of $40 \mathrm{ml} / \mathrm{min}$ and neutrophils above $1.0 \mathrm{G} / \mathrm{L}$ were required. Clinical characteristics and treatment details of the patient cohort are depicted in Table 1. The local ethics committee of Berne, Switzerland with decision \#143/2014 approved this study.

Data sources were medical records of the patients. Neuropathy was assessed by two independent investigators, with T.P. having been one of them for all study patients. In addition, a standardized questionnaire was filled out by all study patients. The questionnaire assessed signs and treatment of neuropathy as well as the subjective disease burden of chemotherapy induced polyneuropathy; it also helped to verify the information retrieved from the medical records. A $100 \%$ response rate was achieved.

\section{Chemomobilization and autologous stem cell transplantation}

Gemcitabine was administered to all patients as a 30 minute infusion at $1250 \mathrm{mg} / \mathrm{m}^{2}$ on day 1 , and filgrastim (G-CSF) was given subcutaneously at a dose of $1 \mathrm{Mio} \mathrm{U} / \mathrm{kg} /$ day divided into two daily doses. G-CSF was started on day 4 and continued until (and including) the day of stem cell collection. Apheresis was triggered at the first day with more than 15'000 CD34+ cells $/ \mathrm{ml}$ in the peripheral blood. $2 \times 10^{6} \mathrm{CD} 34+$ cells $/ \mathrm{kg}$ was the minimum collection requirement, and we aimed to collect between $3-5 \times 10^{6} \mathrm{CD} 34+$ cells $/ \mathrm{kg}$ per transplant, with usually two transplants being planned. Cell processing procedures followed local standards. Patients received single-day high-dose chemotherapy with melphalan administered 
intravenously at a dose of $200 \mathrm{mg} / \mathrm{m}^{2}$, with peripheral stem cell transplantation at the following day.

\section{Definitions}

The two primary objectives of the study were safety and effectiveness of gemcitabine mobilization treatment. We studied CIPN during induction, mobilization, high-dose and maintenance treatment. We assessed incidence, severity, localization, and specific treatment. CIPN was defined as gemcitabine-induced, when patients presented novel or increased symptoms within two weeks after its administration. CIPN during bortezomibbased induction treatment was identified when it occurred between the first bortezomib administration and up to 30 days after the last dose. CIPN was assessed according to the modified version of the National Cancer Institute Common Toxicity Criteria for Adverse Events (NCl-CTCAE; version 4.03). We used the following categories: general sensory neuropathy (paresthesia, dysesthesia, hypesthesia, hyperesthesia, hyporeflexia, hypalgesia, and decreased temperature sensation); neuropathic pain; general motoric neuropathy (muscle weakness); fasciculation (including tremor and spasm); and ataxia. We also investigated the need for specific analgetic CIPN medication as well as modification or interruption of myeloma specific treatment in order to control CIPN symptoms.

\section{Statistical analysis}

We applied descriptive statistics to calculate variables. We summarized the number of observations, median and range for continuous variables, and we calculated the number and percentage of patients in each category for categorical data. Nominal variables were compared with Fisher exact tests. We used non-parametric Mann-Whitney-U tests for continuous variables. The response rates were defined according to the IMWG criteria. OS was the time from transplantat until the date of death from any cause. PFS was the time from transplantat to first progression, relapse or death whichever occurred first. Patients without 
progression or death were censored at their last follow-up. We designed time-to-event estimates (PFS, OS) according to the Kaplan-Meier method using the log-rank (Mantel-Cox) test. Data cut-off date was April 1, 2015. All p-values were two-sided, and a $P$-value of less than .05 was considered statistically significant. We performed all analyses using the GraphPadPrism software (Version 6.0b, GraphPad Software, Inc, San Diego, CA). 


\section{RESULTS}

\section{Patients}

Between 03/2012 and 02/2013, 24 consecutive myeloma patients at the University Hospital in Bern, Switzerland received bortezomib/dexamethasone-based first-line induction treament and subsequent chemomobilization with gemcitabine and G-CSF as per protocol. The patient characteristics at diagnosis and additional information on the chemotherapy regimens are listed in Table 1. The median age at diagnosis of the patients in our cohort was 61 years (range 52-70 years). Patients mostly had IgG subtype (50\%), whereas the type of light chains involved and ISS stages were equally distributed. FISH analyses was available in 17 patients $(71 \%)$. All 24 patients received an induction treatment with bortezomib and dexamethasone (VD). In addition, two patients further received cyclophosphamide (VCD), two patients had doxorubicin (PAD), two patients were also treated with thalidomide (VTD), and two patients received lenalidomide (VRD), respectively.

\section{Stem cell mobilization and transplantation}

Detailed information on mobilization, stem cell collection and transplantation are summarized in Table 2. All patients received gemcitabine at the planned dose of $1250 \mathrm{mg} / \mathrm{m} 2$ at day 1 . None of the patients experienced neutropenia $<0.5 \mathrm{G} / \mathrm{L}$ or thrombocytopenia $<50 \mathrm{G} / \mathrm{L}$ following gemcitabine treatment. No bleeding complications and no febrile episodes requiring antibiotic treatment occurred. Two patients developed edema and weight gain requiring diuretic treatment. Ten of the 24 patients were hospitalized during the stem cell mobilization process, with all hospitalizations related to the application of a central venous catheter line for stem cell harvest, with a median hospitalization duration of two days, ranging from two to four days. In 19 patients (79\%), a single day of apheresis was sufficient to obtain the minimum number of $>2 \times 10^{6} \mathrm{CD} 34+$ cells $/ \mathrm{kg}$, whereas five patients $(21 \%)$ needed two days of stem cell collection. Apheresis was initiated after a median of 8 days (range 8 to 10 days) 
after mobilization with gemcitabine. The total median duration of apheresis was 285 minutes, with a range from 70 to 420 minutes. The median final collection of CD34+ cells was $9.51 \mathrm{x}$ $10^{6}$ cells $/ \mathrm{kg}$, with a range from 4.95 to 19.2 . We found that more than $10 \times 10^{6} \mathrm{CD} 34+$ cells $/ \mathrm{kg}$ b.w. were collected in $54 \%$ of the patients. Finally, none of the patients improved the remission status following gemcitabine treatment.

All patients in this study underwent subsequent high-dose chemotherapy with $200 \mathrm{mg} / \mathrm{m} 2$ melphalan, with peripheral stem cell transplantation at the following day. The patients received a median of $3.4 \times 10^{6} \mathrm{CD} 34+$ cells $/ \mathrm{kg}$ (range 2.0 to 5.4). All patients had successful engraftment. The median time to recovery was 11 days (range 11 to 13 days) for neutrophils (ANC > $0.5 \mathrm{G} / \mathrm{l}$ ), 13 days (range 9 to 21 days) for platelets $>20 \times 10^{9} / \mathrm{l}$, and 20 days (range 15 to 40 days) for platelets $>100 \times 10^{9} /$. Maintenance treatment after ASCT was given in 15 patients (63\%), with lenalidomide in all these patients.

\section{Chemotherapy induced polyneuropathy (CIPN)}

The incidence of CIPN during induction and mobilization treatment is summarized in Table 3. In one patient (5\%), polyneuropathy was pre-existing, most likely due to diabetes mellitus in this patient. Evaluation of clinical assessment together with the patient questionnaire indicated that any signs of clinical manifestation of CIPN during bortezomib-based induction treatment occurred in 21 of 24 myeloma patients $(88 \%)$. We found that the differences observed in the total incidence of CIPN as documented by the treating physicians in their medical charts compared to the data retrieved from individual questionnaires were not significant $(P=.45)$.

Symptoms of CIPN were first reported after a mean of 6.88 weeks of bortezomib treatment. As depicted in Table 4, CIPN affected patients predominantly reported sensory symptoms $(68 \%)$, with grade $\mathrm{I} / \mathrm{II}$ in $48 \%$ and grade III/IV in $20 \%$. Motoric symptoms were documented in 7 patients (28\%), all being grade I or II. Ataxia was identified in two patients (8\%). Standard medication given for neuropathic pain involved pregabalin, gabapentin and 
opioids. Finally, four patients $(16 \%)$ of the patients needed bortezomib dose reduction, prolongation of treatment interval or even interruption of therapy as a consequence of the occurrence of bortezomib-induced CIPN. In two patients (8\%), CIPN resulted in the premature discontinuation of bortezomib treatment. However, none of the patients in this study received a second line of chemotherapy, for whatever reason, before mobilization treatment.

Noteworthy, we observed only one patient (4\%) with worsening of bortezomibinduced sensory CIPN (from grade I to II) during and following mobilization treatment with gemcitabine. Also, a single patient $(4 \%)$ reported worsening of bortezomib-induced sensory CIPN (from grade I to II) following high-dose chemotherapy. During lenalidomide maintenance treatment, two patients (8\%) had worsening of CIPN (one patient from grade I to II, and one patient from grade II to III) as summarized in Table 4.

Repetitive follow-up information on the course of CIPN was available for all patients. Symptoms of CIPN resolved in $14 \%$ of all patients $(n=3)$ until the day 100 assessment after HDCT. In additional 9 (41\%) patients, symptoms gradually improved over time with a median time to disappearance of 5 months (range 4 to 9 months). However, $18 \%$ of the patients $(n=4)$ only had a partial improvement of CIPN, and $27 \%$ of the patients $(n=6)$ considered CIPN still present and a "major problem". Patients described a "very high burden" due to CIPN in $23 \%$, and a "high burden" in another $23 \%$. For $45 \%$ of the patients, CIPN was "tolerable and modest", whereas only 9\% considered it "harmless" (data not shown).

\section{Outcome}

Information on outcome is limited by the small number of study patients. Consequently, we observed no significant differences in response rates at mobilization and 100 days after ASCT when comparing patients with and without CIPN before ASCT. Eight of all 24 study patients so far had a relapse after ASCT, with the median relapse-free survival being not yet reached after a median follow-up of 31 months. The relapse-free survival two years after 
ASCT was $72 \%$. Figure $1 \mathrm{~A}$ depicts the relapse-free survival (RFS) of the entire study cohort, and Figure 1B indicates the overall survival (OS). Two patients died so far, after 10 and 13 months, in both cases due to myeloma progression. Again, the median survival of the entire study cohort was not yet reached, and the median overall survival after two years was $92 \%$. 


\section{DISCUSSION}

Bortezomib based regimens for first-line induction treatment have improved remission and survival rates in myeloma patients and have become standard of care (Richardson et al, 2003; Sonneveld et al, 2013). However, chemotherapy-induced polyneuropathy (CIPN) is a major and often limiting side effect of bortezomib (Argyriou et al, 2008; Delforge et al, 2010; Keller et al, 2015; Koeppen et al, 2014; Mohty et al, 2010; Richardson et al, 2006). In our study cohort, $88 \%$ of myeloma patients treated with subcutaneous bortezomib developed clinical signs of neuropathy of any grade which led in $16 \%$ to prolongation of treatment intervals or discontinuation of bortezomib treatment. The majority of the patients had sensory deficits which is consistent with previous reports on bortezomib inducing a dose-related peripheral, mainly sensory polyneuropathy with accompanying neuropathic pain (Argyriou et al, 2008; Delforge et al, 2010; Keller et al, 2015; Koeppen et al, 2014; Mohty et al, 2010; Richardson et al, 2006). Thus, optimized concepts for the prevention and treatment of bortezomib induced CIPN are obviously essential for myeloma patients, and such strategies involve subcutaneous application, the once weekly administration, and timely discontinuation at early signs of neuropathy to enable reversibility of symtoms (Argyriou et al, 2008; Cavaletti et al, 2010; Stubblefield et al, 2009).

Bortezomib associated CIPN is significantly affecting the quality of life of myeloma patients. The majority (63\%) of myeloma patients affected by CIPN in our study considered the burden of CIPN as "high" or "very high", and more than half of the patients with CIPN failed to completely recover from CIPN, with $31 \%$ reporting unchanged persisting CIPN after completion of HDCT treatment.

Based on these considerations, we evaluated an alternative chemomobilization approach after bortezomib induction. Traditionally, the standard strategy in Switzerland to mobilize peripheral autologous stem cells in myeloma patients is a single-dose of $35 \mathrm{mg} / \mathrm{m} 2$ vinorelbine, with G-CSF stimulation initiated four days later (Bargetzi et al, 2003; Heizmann et al, 2009; Samaras et al, 2015; Schmid et al, 2015). This non-myelosuppressive concept 
allows a highly reliable and efficient stem cell collection at day 8 . This concept has been challenged in the last years with the predominant use of bortezomib during induction treatment and with bortezomib induced polyneuropathy (CIPN) as its major side effect. The vinca-alkaloid vinorelbine is mediating additional neurotoxicity (Capasso et al, 2012; Galano et al, 2011; Lobert et al, 1996), involving hypoesthesia, hyporeflexia, paresthesia and pain, but also motoric or autonomic axons can be dammaged, which is similar to the neurotoxic profile of bortezomib (Capasso et al, 2012; Galano et al, 2011; Lobert et al, 1996). In fact, we previously reported that a single dose of vinorelbine can significantly aggravate bortezomib induced CIPN - or induce first manifestation of CIPN - in bortezomib pretreated myeloma patients (Keller et al, 2015). These observations formed the basis of our study to evaluate an alternative chemomobilization approach while preserving the advantages of a nonmyelosuppressive strategy.

Gemcitabine is a promising candidate for chemomobilization. It has been studied so far as a component of a polychemotherapy mobilization strategy in relapsed Hodgkin lymphoma patients and has been considered both safe and effective (Suyani et al, 2011). However, it has not been used so far as monochemotherapy for mobilization of autologous stem cells. We found that a single dose of $1250 \mathrm{mg} / \mathrm{m} 2$ gemcitabine - together with G-CSF stimulation started at day 4 after gemcitabine - was effective to allow the collection of autologous stem cells in all 24 study patients. Consequently, all patients proceeded to subsequent high-dose chemotherapy treatment and enjoyed timely hematologic recovery and no unexpected infectious or toxic complications. Importantly, we did not observe significant aggravation of bortezomib-induced CIPN - or first occurrence of CIPN - in bortezomib-pretreated myeloma patients following the administration of gemcitabine. These observations suggest that gemcitabine can safely replace vinorelbine for chemomobilization of autologous stem cells in bortezomib-pretreated myeloma patients.

High-dose cyclophosphamide chemotherapy with G-CSF represents the most commonly used chemomobilization regimen. Our data suggest that the combination of GCSF with a single dose of non-myelosuppressive chemotherapy with gemcitabine compares 
favorably to cyclophosphamide mobilization because of its reliable and predictable collection rate at day 8 , the strictly ambulatory setting, and the lack of febrile complications notoriously associated with cyclophosphamide mobilization.

We undertook considerable efforts to identify CIPN during induction and mobilization chemotherapy, but also during high-dose chemotherapy and lenalidomide maintenance treatment. All patients were clinically monitored for the development and assessment of the severity of CIPN, and patients also reported their observations using a standardized questionnaire. The finding of $88 \%$ of all patients showing signs of CIPN after bortezomib induction treatment in this small study appears high compared to other larger series, Thus, a by chance effect due to the small sample size may have contributed to this high incidence. However, our study points to the possibility that CIPN may remain unrecognized by both treating physicians and patients unaware of the variety of CIPN symptoms.

We observed one patient with aggravation of bortezomib-induced CIPN (from grade I to II) after gemcitabine, one patient after high-dose melphalan chemotherapy, and two patients under lenalidomide maintenance treatment. These observations underline the concept that gemcitabine mobilization, high-dose melphalan and lenalidomide maintenance are not neurotoxic myeloma treatments, and the rare observation of novel neuropathy in bortezomib-pretreated patients suggests the possibility of other mechanisms. Recently, late onset of previously not overt bortezomib induced polyneuropathy was observed, emerging mainly during or shortly after peripheral blood stem cell (PBSC) collection (Tacchetti et al, 2014). A coasting phenomenon of bortezomib was suggested rather than an effect of compounds used between bortezomib-based induction treatment and PBSC collection (Tacchetti et al, 2014). Possibly, such late occurrence of bortezomib toxicity may have been involved in the few patients with CIPN occurring after discontinuation of beortezomib treatment.

We identified a slow recovery rate from bortezomib triggered polyneuropathy. In fact, half of all affected patients continued to suffer from symptoms of disabling CIPN after completion of HDCT treatment. Previous reports suggested that bortezomib (or vinorelbine-) 
induced neuropathy was predominantly reversible after drug discontinuation within two to four months (Argyriou et al, 2008; Koeppen et al, 2014; Mohty et al, 2010). In contrast, improvement of CIPN in our cohort remained incomplete in a significant proportion of patients. In the absence of effective treatment modalities for CIPN, prevention of severe CIPN remains an important goal of induction treatment in myeloma patients (Cavaletti et al, 2010; Mantyh et al, 2006; Stubblefield et al, 2009).

This study was not powered to evaluate the effect of the development of CIPN on response and survival rates. In fact, we observed no differences in response and survival rates between myeloma patients with and without CIPN. However, developing CIPN can affect dosing, duration and the chemotherapy composition of later myeloma treatment thereby affecting response to treatment (Cavaletti et al, 2010; Mantyh et al, 2006; Stubblefield et al, 2009). Consequently, longer follow-up of a larger cohort may be required to ultimately provide answers to these issues. However, our data suggest that gemcitabine represents a promising alternative candidate to replace neurotoxic vinorelbine chemomobilization. Consequently, we initiated a randomized prospective trial comparing vinorelbine and gemcitabine mobilization chemotherapy in myeloma patients, and this trial may ultimately identify a novel role for gemcitabine as a non-neurotoxic and effective stem cell mobilization regimen in myeloma patients. 


\section{ACKNOWLEDGEMENTS}

We wish to thank Marion Bleckmann, Barbara Muster and Irene Briner for help with stem cell data collection, Myriam Legros for providing CD34+ data, and Anke Klingenberg-Rettich and Doris Jaeggi for help with data collection on clinical outcome.

\section{CONTRIBUTIONS}

Performed research, analyzed data and wrote the paper (BUM);

performed research, read and approved the final version of the manuscript (SK);

contributed vital material, read and approved the final version of the manuscript (BMT);

analyzed data, read and approved the final version of the manuscript (KS);

contributed vital material, read and approved the final version of the manuscript (DR);

contributed vital material, read and approved the final version of the manuscript (DB);

contributed vital material, read and approved the final version of the manuscript (TE);

designed research, analyzed data and wrote the paper (TP).

\section{FUNDINGS}

This work was supported by a grant from the Bernische Stiftung für Klinische Krebsforschung (to TP), from the Krebsliga Bern (to TP), and from the EMPIRIS Foundation/Ursula-HechtFonds (to TP).

\section{CONFLICT OF INTEREST}

The authors declare no conflict of interest. 


\section{REFERENCES}

Argyriou AA, Iconomou G, Kalofonos HP (2008) Bortezomib-induced peripheral neuropathy in multiple myeloma: a comprehensive review of the literature. Blood 112: 1 - 11.

Bargetzi MJ, Passweg J, Baertschi E, Schoenenberger A, Gwerder C, Tichelli A, Burger J, Mingrone W, Herrmann R, Gratwohl A, Wernli M (2003) Mobilization of peripheral blood progenitor cells with vinorelbine and granulocyte colony-stimulating factor in multiple myeloma patients is reliable and cost effective. Bone Marrow Transplant 31: 99 - 103.

Blade J, Rosinol L, Sureda A, Ribera JM, Mediavilla J, Garcia-Larana J, Mateos MV, Palomera L, Fernandez-Calvo J, Marti JM, Giraldo P, Carbonell F, Callis M, Trujillo J, Gardella S, Moro MJ, Barez A, Soler A, Font L, Fontanillas M, San MJ (2005) High-dose therapy intensification compared with continued standard chemotherapy in multiple myeloma patients responding to the initial chemotherapy: long-term results from a prospective randomized trial from the Spanish cooperative group PETHEMA. Blood 106: 3755 - 3759.

Capasso A (2012) Vinorelbine in cancer therapy. Current Drug Targets 13: 1065 - 1071.

Carlson K, Ocean AJ (2011) Peripheral neuropathy associatd with microtubule-targeting agents: occurence and management approach. Clinical Breast Cancer 11: 73 - 81.

Cavaletti G, Jakubowiak AJ (2010) Peripheral neuropathy during bortezomib treatment of multiple myeloma: a review of recent studies. Leuk Lymphoma 51: 1178 - 1187.

Delforge M, Bladé J, Dimopoulos MA, Facon T, Kropff M, Ludwig H, Palumbo A, Van Damme P, San-iguel JF, Sonneveld P (2010) Treatment-related peripheral neuropathy in multiple myeloma: the challenge continues. Lancet Oncol 11: 1086 - 1095.

Fermand JP, Katsahian S, Divine M, Leblond V, Dreyfus F, Macro M, Arnulf B, Royer B, Mariette X, Pertuiset E, Belanger C, Janvier M, Chevret S, Brouet JC, Ravaud P (2005) High-dose therapy and autologous blood stem-cell transplantation compared with conventional treatment in myeloma patients aged 55 to 65 years: long-term results of a randomized control trial from the Group Myeloma Autogreffe. J Clin Oncol 23: 9227 - 9233.

Galano G, Caputo M, Tecce MF, Capasso A (2011) Efficacy and Tolerability of Vinorelbine in the Cancer Therapy. Current Drug Safety 6: 185 - 193.

Giralt S, Stadtmauer EA, Harousseau JL, Palumbo A, Bensinger W, Comenzo RL, Kumar S, Munshi NC, Dispenzieri A, Kyle R, Merlini G, San Miguel J, Ludwig H, Hajek R, Jagannath S, 
Blade J, Lonial S, Dimopoulos MA, Einsele H, Barlogie B, Anderson KC, Gertz M, Attal M, Tosi P, Sonneveld P, Boccadoro M, Morgan G, Sezer O, Mateos MV, Cavo M, Joshua D, Turesson I, Chen W, Shimizu K, Powles R, Richardson PG, Niesvizky R, Rajkumar SV, Durie BG (2009) International myeloma working group (IMWG) consensus statement and guidelines regarding the current status of stem cell collection and high-dose therapy for multiple myeloma and the role of plerixafor (AMD 3100). Leukemia 23: 1904 - 1912.

Harousseau JL, Moreau P (2009) Autologous hematopoietic stem-cell transplantation for multiple myeloma. N Engl J Med 360: 2645 - 2654.

Heizmann M, O'Meara AC, Moosmann PR, Heijnen IA, Zuberbühler M, Fernandez P, Burger J, Huber A, Wernli M, Bargetzi MJ (2009) Efficient mobilization of PBSC with vinorelbine/GCSF in patients with malignant lymphoma. Bone Marrow Transplant 44: 75 - 79.

Keller S, Seipel K, Novak U, Mueller BU, Taleghani BM, Leibundgut K, Pabst T (2015) Neurotoxicity of stem cell mobilization chemotherapy with vinorelbine in myeloma patients after bortezomib treatment. Leuk Res accepted.

Koeppen S (2014) Treatment of Multiple Myeloma: Thalidomide-, bortezomib-, and lenalidomide-induced peripheral neuropathy. Oncol Res Treat 37: 506 - 513.

Lobert S, Vulevic B, Correia JJ (1996) Interaction of vinca alkaloids with tubulin: a comparison of vinblastin, vincristine, and vinorelbine. Biochemistry 31: 5374 - 5380.

Ludwig H, Beksac M, Bladé J, Boccadoro M, Cavenagh J, Cavo M, Dimopoulos M, Drach J, Einsele H, Facon T, Goldschmidt H, Harousseau JL, Hess U, Ketterer N, Kropff M, Mendeleeva L, Morgan G, Palumbo A, Plesner T, San Miguel J, Shpilberg O, Sondergeld P, Sonneveld P, Zweegman S (2010) Current Multiple Myeloma Treatment Strategies with Novel Agents: A European Perspective. The Oncologist 15: 6 - 25.

Mantyh PW (2006) Cancer pain and its impact on diagnosis, survival and quality of life. Nature Rev Neuroscience 7: 797 - 809.

Mohty B, El-Cheikh J, Yakoub-Agha I, Moreau P, Harousseau JL, Mohy M (2010) Peripheral neuropathy and new treatments for multiple myeloma: background and practical recommendations. Haematologica 95: 311 - 319.

Rajkumar SV (2011) Multiple myeloma: 2012 update on diagnosis, risk-stratification, and management. American J Hemat 87: 79 - 88. 
Richardson PG, Barlogie B, Berenson J, Singhai S, Jagannath S, Irwin D, Rajkumar SV, Srkalovic G, Alsina M, Alexanian R, Siegel D, Orlowski RZ, Kuter D, Limentani SA, Lee S, Hideshima T, Esseltine DL, Kauffman M, Adams J, Schenkeln DP, Anderson KC (2003) A phase 2 study of bortezomib in relapsed, refractory myeloma. N Engl J Med 348: 2609 2617.

Richardson PG, Briemberg H, Jagannath S, Wen PY, Barlogie B, Berenson J, Singhai S, Siegel DS, Irwin D, Schuster M, Srkalovic G, Alexanian R, Rajkumar SV, Limentani S, Alsina M, Orlowski RZ, Najarian K, Esseltine D, Anderson KC, Amato AA (2006) Frequency, characteristics, and reversibility of peripheral neuropathy during treatment of advanced multiple myeloma with bortezomib. J Clin Oncol 24: 3113 - 3120.

Samaras P, Pfrommer S, Seifert B, Petrausch U, Mischo A, Schmidt A, Bargetzi M (2015) Efficacy of vinorelbine plus G-CSF for CD34+ hematopoietic progenitor cell mobilization in patients with multiple myeloma. Biol Blood Marrow Transplant 21: 74 - 80.

Schmid A, Friess D, Mansouri Taleghani B, Keller P, Mueller BU, Baerlocher GM, Leibundgut K, Pabst T (2015) Role of plerixafor in autologous stem cell mobilization with vinorelbine chemotherapy and granulocyte-colony stimulating factor in patients with myeloma: a phase II study (PAV-trial). Leuk Lymphoma 56: 608-614.

Sonneveld P, Goldschmidt H, Rosinol L, Bladé J, Lahuerta JJ, Cavo M, Tacchetti P, Zamagni E, Attal M, Lokhorst HM, Desai A, Cakana A, Liu K, van de Velde H, Eseltine D, Moreau P (2013) Bortezomib-based versus nonbortezomib-based induction treatment before autologous stem-cell transplantation in patients with previously untreated multiple myeloma: a meta-analysis of phase III randomized, controlled trials. J Clin Oncol 31: 3279 - 3288.

Stubblefield MD, Burstein HJ, Burton AW, Custodio CM, Deng GE, Ho M, Junck L, Stephen Morris G, Paice JA, Tummala S, Von Roenn JH (2009) NCCN Task force report: management of neuropathy in cancer. J Natl Compr Canc Netw 7: 1 - 26.

Suyani E, Sucak GT, Aki SZ, Yegin ZA, Özkurt ZN, Yagci M (2011) Gemcitabine and vinorelbine combination is effective in both as a salvage and mobilization regimen in relapsed or refractory Hodgkin lymphoma prior to ASCT. Ann Hematol 90: 658 - 691.

Swain SM, Arezzo JC (2008) Neuropathy associated with microtubule inhibitors: diagnosis, incidence, and management. Clin Adv Hematol Oncol 6: 455 - 467.

Tacchetti P, Terragna C, Galli M, Zamagni E, Petrucci MT, Pezzi A, Montefusco V, Martello M, Tosi P, Baldini L, Pecatori J, Ruggieri M, Pantani L, Lazzaro A, Elice F, Rocchi S, 
Gozzetti A, Palumbo A, Cavaletti G, Cavo M (2014) Bortezomib- and thalidomide-induced peripheral neuropathy in multiple myeloma: clinical and molecular analyses of a phase 3 study. American J Hemat 89: 1085-1091.

1

2

3

4

5

6

7

8

9

10

11

12

13

14

15

16

17

18

19

20

21

22

23

24

25

26

27

28

29

30

31

32

33

34

35

36

37

38

39

40

41

42

43

44

45

46

47

48

49

50

51

52

53

54

55

56

57

58

59

60 


\section{TITLES AND LEGENDS TO FIGURES}

Figure 1: A) Kaplan-Meier curves are depicted for the relapse-free survival (RFS) and B) for the overall survival (OS) of the entire study cohort. 
Figure 1

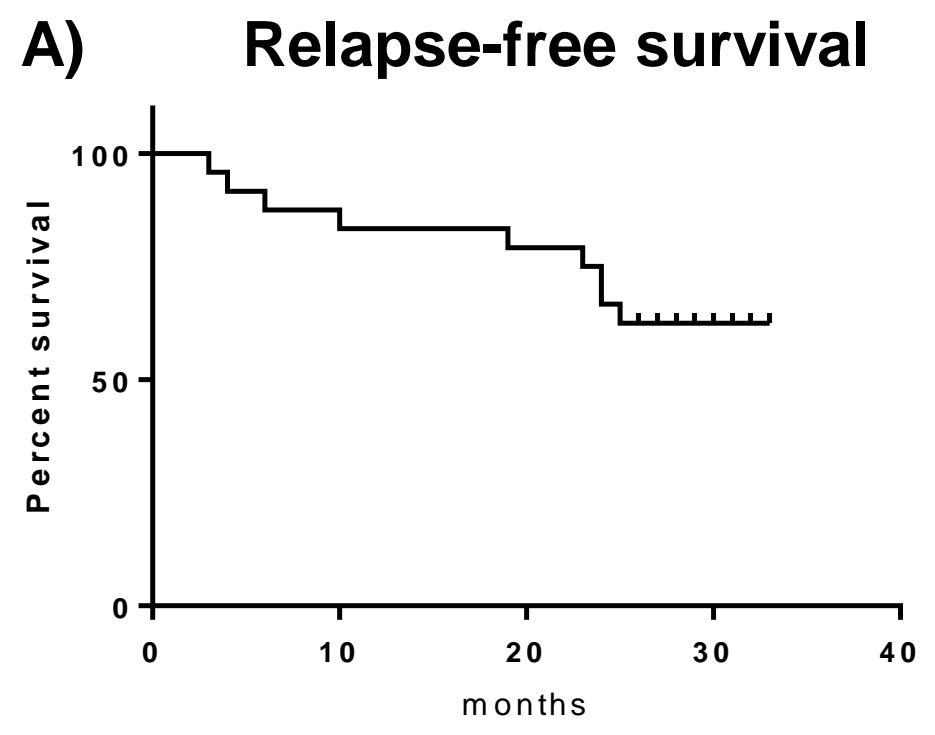

B) Overall survival

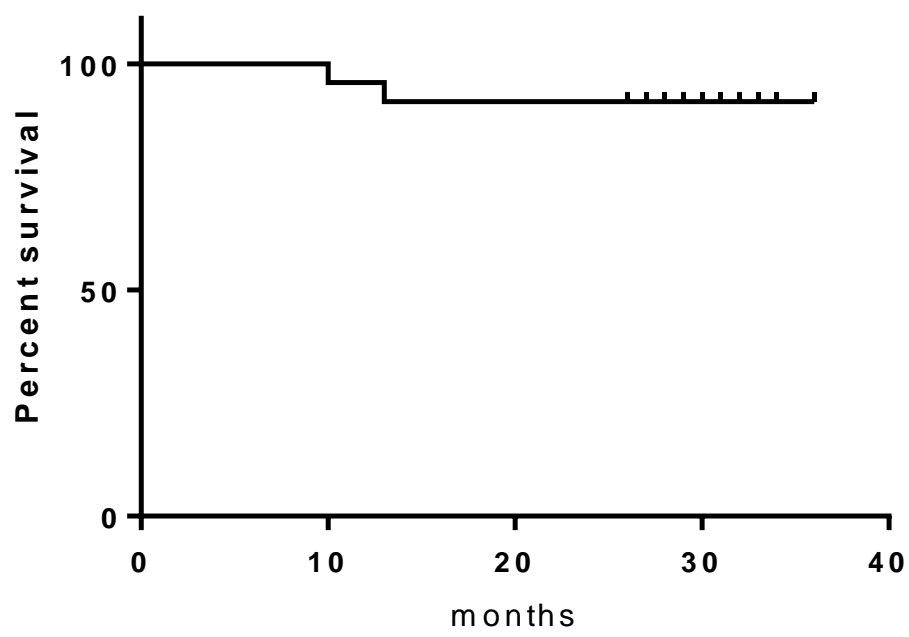




\section{Table 1 - Patient characteristics}

\begin{tabular}{|c|c|}
\hline & $n=24$ \\
\hline age at diagnosis; median $\left(\mathrm{y}^{\mathrm{a}}\right.$, range $)$ & $61(52-70)$ \\
\hline sex, m/f; n (\%) & $13 / 11(54 / 46)$ \\
\hline $\operatorname{lgG} n(\%)$ & $12(50)$ \\
\hline $\lg A$ n (\%) & $7(29)$ \\
\hline $\operatorname{lgD} \mathrm{n}(\%)$ & $1(4)$ \\
\hline light-chain only & $3(13)$ \\
\hline asecretory & $1(4)$ \\
\hline kappa & $12(50)$ \\
\hline lambda & $12(50)$ \\
\hline stage Durie \& Salmon I & $8(33)$ \\
\hline II & $7(29)$ \\
\hline III & $9(38)$ \\
\hline A & $17(71)$ \\
\hline $\mathrm{B}$ & $7(29)$ \\
\hline Stage ISS I & $8(33)$ \\
\hline II & $7(29)$ \\
\hline III & $9(38)$ \\
\hline FISH/cytogenetics ${ }^{\mathrm{b}}$ : not done & $7(29)$ \\
\hline trisomies & $12(50)$ \\
\hline tetrasomy 9 & $1(4)$ \\
\hline deletion 1q & $2(8)$ \\
\hline deletion $13 q$ & $6(24)$ \\
\hline deletion $17 p$ & $5(20)$ \\
\hline monosomy 4 & $1(4)$ \\
\hline monosomy 14 & $1(4)$ \\
\hline $\mathrm{t}(4 ; 14)$ & $2(8)$ \\
\hline$t(14 ; 18)$ & $1(4)$ \\
\hline$t(14 ; 16)$ & $3(13)$ \\
\hline \multicolumn{2}{|l|}{ Induction treatment } \\
\hline bortezomib/dexamethason-based (VD) & $24(100)$ \\
\hline + cyclophosphamide (VCD) & $16(68)$ \\
\hline + anthracyclin (PAD) & $2(8)$ \\
\hline + thalidomide (VTD) & $2(8)$ \\
\hline + lenalidomide (RVD) & $2(8)$ \\
\hline VD & $2(8)$ \\
\hline cycles, median (mean) & $4(3.67)$ \\
\hline range & $2-6$ \\
\hline second induction regimen & $0(0)$ \\
\hline maintenance treatment: none & $9(37)$ \\
\hline with lenalidomide & $15(63)$ \\
\hline duration months, median (mean) & $12(14)$ \\
\hline range & $2-24$ \\
\hline
\end{tabular}

${ }^{\mathrm{a}} \mathrm{y}$ : years; ${ }^{\mathrm{b}} 7$ patients had multiple findings. 
Table 2: Mobilization and transplantation.

\begin{tabular}{|c|c|}
\hline $\begin{array}{l}\text { gemcitabine chemotherapy + G- } \\
\text { CSF, } n(\%)\end{array}$ & $24(100)$ \\
\hline one day of apheresis & $19(79)$ \\
\hline two days of apheresis & $5(21)$ \\
\hline 1st apheresis at day 8 & $16(67)$ \\
\hline 1st apheresis at day 9 & $7(29)$ \\
\hline 1st apheresis at day 10 & $1(4)$ \\
\hline median (mean) & $8(8.38 \pm 0.57)$ \\
\hline duration of apheresis, mean, minutes & $269.71 \pm 91.27$ \\
\hline median, minutes (range) & $285(70-420)$ \\
\hline mean blood volume processed, liters & 26.2 \\
\hline median, liters (range) & $25.3(13.5-33.9)$ \\
\hline leukocytes at apheresis ${ }^{a}$, mean $(G / l)$ & $33.80 \pm 12.94$ \\
\hline median (range) & $34.4(7.90-55.6)$ \\
\hline \multicolumn{2}{|l|}{ peripheral CD34-Wert at apheresis ${ }^{a}$} \\
\hline mean $\left(\times 10^{9} / \mathrm{ml} \mathrm{PB}\right)$ & $56.3 \pm 38.1$ \\
\hline median, x 106 / ml PB (range) & $50.5(4.4-122.4)$ \\
\hline \multicolumn{2}{|l|}{$\%$ CD34 leukocytes at apheresis ${ }^{a}$} \\
\hline mean & $0.19 \pm 0.32$ \\
\hline median (range) & $0.14(0.02-0.68)$ \\
\hline \multicolumn{2}{|l|}{ total collected CD $34+x 10^{6} / \mathrm{kg} \mathrm{b} .{ }^{d}{ }^{d}$} \\
\hline mean & $10.09 \pm 6.61$ \\
\hline median (range) & $9.51(4.95-19.2)$ \\
\hline $\begin{array}{l}\text { patients with }>5 \times 10^{6} / \mathrm{kg} \mathrm{CD} 34+ \\
\text { cells after the } 1^{\text {st }} \text { day of apheresis }\end{array}$ & $23(96)$ \\
\hline \multicolumn{2}{|l|}{ transfused CD $34+x 10^{6} / \mathrm{kg} \mathrm{b.w.}{ }^{\mathrm{d}}$} \\
\hline mean & $3.51 \pm 0.97$ \\
\hline median (range) & $3.4(2.0-5.4)$ \\
\hline \multicolumn{2}{|l|}{ first day of $A N C^{b}>0,5 \times 109 / L-n(\%)$} \\
\hline day 11 & $14(58)$ \\
\hline day 12 & $9(38)$ \\
\hline day 13 & $1(4)$ \\
\hline mean & $11.46 \pm 0.58$ \\
\hline median (range) & $11(11-13)$ \\
\hline \multicolumn{2}{|l|}{ first day of PIts ${ }^{c}>20 \times 109 / L-n(\%)$} \\
\hline days $10-12$ & $5(21)$ \\
\hline day 13 & $8(33)$ \\
\hline days $14-15$ & $9(38)$ \\
\hline >day 15 & $2(8)$ \\
\hline mean & $13.63 \pm 2.27$ \\
\hline median (range) & $13(9-21)$ \\
\hline \multicolumn{2}{|l|}{ first day of Plts ${ }^{c}>100 \times 109 / L-n(\%)$} \\
\hline$\leq$ day 20 & $13(54)$ \\
\hline days $20-30$ & $8(33)$ \\
\hline$>$ day 30 & $3(12)$ \\
\hline mean & $22.04 \pm 5.88$ \\
\hline median (range) & $20(15-40)$ \\
\hline
\end{tabular}

\footnotetext{
${ }^{a}$ at the first day of apheresis; ${ }^{b}$ ANC: absolute neutrophil count; ${ }^{c}$ Plts; platelets; in the absence for transfusions in the previous three days; ${ }^{\mathrm{d}}$ b.w.: body weight.
} 


\section{Table 3: Outcome}

\begin{tabular}{lc}
\hline Remission status at transplantation & \\
stable disease & $1(4)$ \\
partial remission & $10(42)$ \\
very good partial remission & $12(50)$ \\
complete remission & $1(4)$ \\
100 days after transplant & \\
complete remission & $13(54)$ \\
not in complete remission & $11(46)$ \\
Relapse, n (\%) & $8(33)$ \\
Death due to progression, $\mathrm{n}(\%)$ & $2(8)$ \\
Follow-up, mean, months & $26 \pm 4.82$ \\
median (range) & $31(26-36)$ \\
\end{tabular}

${ }^{a}$ Two patients died, both due to myeloma progression. 
Table 4: Peripheral neuropathy (PN).

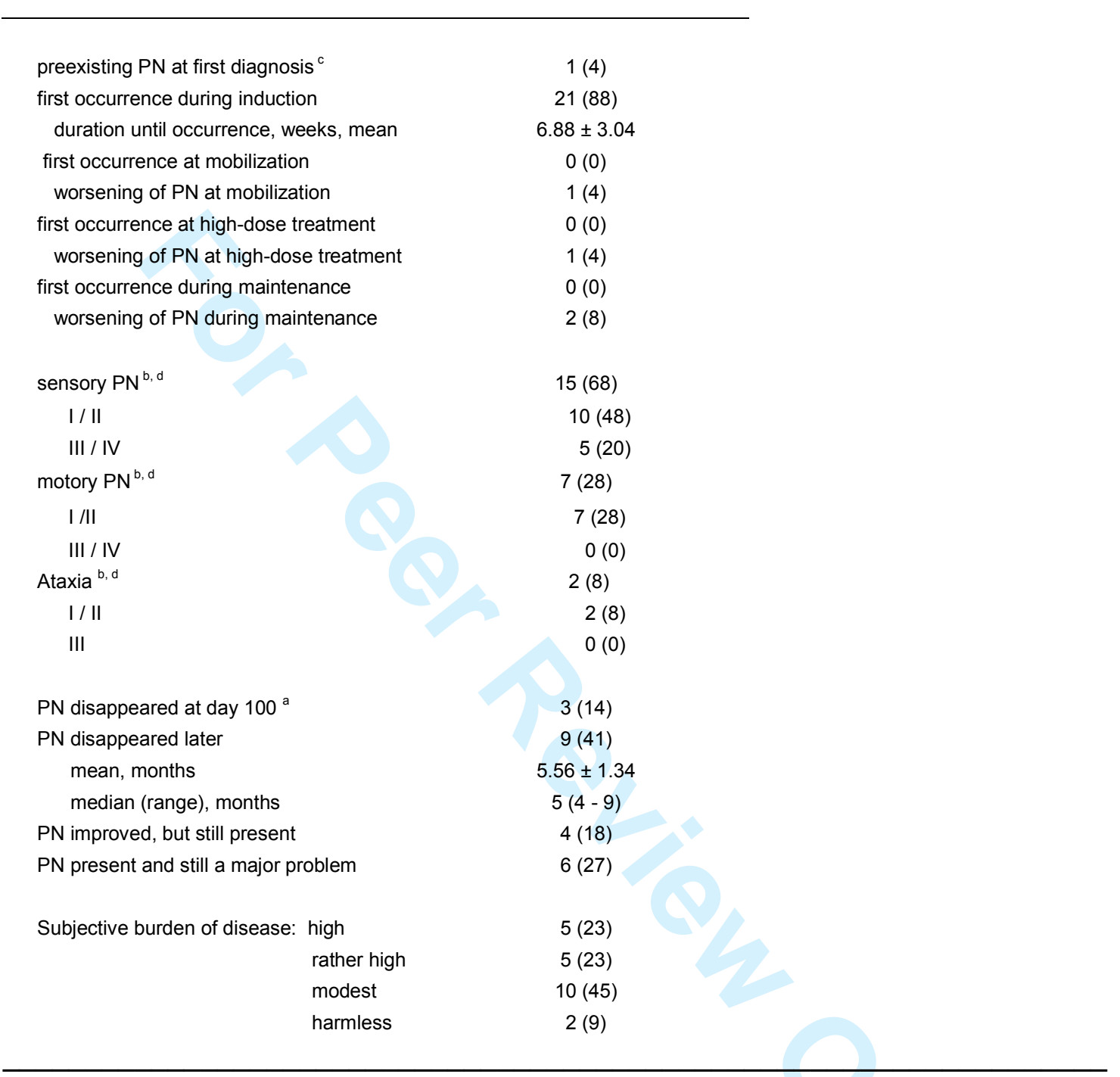

${ }^{a}$ At 100 days after high-dose chemotherapy; ${ }^{b}$ three patients had more than one quality of PN; ${ }^{c} \mathrm{PN}$ : polyneuropathy; ${ }^{d}$ maximum degree observed. 


\title{
Stem cell mobilization chemotherapy with gemcitabine is effective and safe in myeloma patients with bortezomib induced neurotoxicity.
}

\begin{abstract}
AUTHORS: ${ }^{1}$ Beatrice U. Mueller, ${ }^{2}$ Sandra Keller, ${ }^{1}$ Katja Seipel, ${ }^{3}$ Behrouz Mansouri Taleghani, ${ }^{4}$ Daniel Rauch, ${ }^{5}$ Daniel Betticher, ${ }^{6}$ Thomas Egger, ${ }^{2}$ Thomas Pabst.

AFFILIATIONS: ${ }^{1}$ Department of Clinical Research, University of Berne; Berne, Switzerland; ${ }^{2}$ Department of Medical Oncology, University Hospital of Berne; Berne, Switzerland; ${ }^{3}$ Department of Hematology, University Hospital of Berne; Berne, Switzerland; ${ }^{4}$ Department of Oncology; Kantonsspital; Thun, Switzerland; ${ }^{5}$ Department of Oncology; Kantonsspital; Fribourg, Switzerland; and ${ }^{6}$ Department of Oncology; Kantonsspital; Solothurn, Switzerland.
\end{abstract}

RUNNING HEAD: Gemcitabine for mobilization in myeloma.

\begin{abstract}
ABBREVIATIONS: MM: multiple myeloma; HDCT: high-dose chemotherapy; ASCT: autologous stem cell transplantation; G-CSF: granulocyte-colony stimulating factor; PN: peripheral neuropathy; CIPN: chemotherapy-induced peripheral neuropathy; BIPN: bortezomib-induced peripheral neuropathy; OS: overall survival; PFS: progression-free survival.
\end{abstract}

MANUSCRIPT DETAILS: abstract: 199 words (200 allowed); manuscript word count: 2832 words (3'000 allowed); 4 tables; 1 figure; no supplemental material; 27 references.

CORRESPONDING AUTHOR: Thomas Pabst MD; Associate Professor; Department of Medical Oncology; University Hospital; Berne; Switzerland. Phone: ++41 31632 8430; fax: ++4131632 3410; Email: thomas.pabst@insel.ch. 


\section{SUMMARY}

Background: Vinorelbine chemotherapy with G-CSF stimulation is a widely applied nonmyelosuppressive mobilization regimen in Switzerland for myeloma patients, but its neurotoxic potential limits its use in patients with bortezomib induced polyneuropathy.

Methods: In this single-center study, we alternatively evaluated safety and effectiveness of gemcitabine chemotherapy with G-CSF for mobilization of autologous stem cells.

Results: Between 03/2012 and 02/2013, all bortezomib pretreated myeloma patients planned to undergo first-line high-dose melphalan chemotherapy received a single dose of $1250 \mathrm{mg} / \mathrm{m} 2$ gemcitabine, with G-CSF started on day four. The 24 patients in this study have received a median of four cycles of bortezomib-dexamethason based induction. Bortezomibcaused polyneuropathy was identified in 21 patients $(88 \%)$ by clinical evaluation and a standardized questionnaire. Administration of gemcitabine mobilization did not induce novel or aggravate preexisting neuropathy. Stem cell mobilization was successful in all 24 patients, with a single day of apheresis being sufficient in 19 patients $(78 \%)$. The median yield was $9.51 \times 10^{6} \mathrm{CD} 34+$ cells $/ \mathrm{kg}$. Stem collection could be accomplished at day 8 in $67 \%$.

Conclusion: Our data suggest that single-dose gemcitabine together with G-CSF is an effective mobilization regimen in myeloma patients and a safe alternative nonmyelosuppressive mobilization chemotherapy for myeloma patients with bortezomib induced polyneuropathy.

KEY WORDS: mobilization; stem cells; myeloma; polyneuropathy; gemcitabine; bortezomib; neurotoxicity; autologous; transplant. 


\section{INTRODUCTION}

Significant advances have been reported in the treatment of myeloma patients in the last decades. The introduction of proteasome inhibitors and immunomodulatory compounds for induction treatment, high-dose chemotherapy (HDCT) followed by autologous stem cell transplantation (ASCT) for consolidation, and subsequent maintenance treatment with lenalidomide or bortezomib have increased remission and survival rates in myeloma patients (Bladé et al, 2005; Fernand et al, 2005; Giralt et al, 2011; Harrousseau et al, 2009; Ludwig et al, 2010; Rajkumar, 2011). Noteworthy, a number of studies identified an independent benefit of first-line HDCT with ASCT also in the era of novel agents, which was further enhanced by maintenance treatment after HDCT (Bladé et al, 2005; Fernand et al, 2005; Giralt et al, 2011; Harrousseau et al, 2009). These observations indicate that ASCT continues to be a component of the first-line treatment algorithm for young and fit myeloma patients (Harrousseau et al, 2009; Ludwig et al, 2010).

The optimal strategy to mobilize autologous stem cells from the bone marrow to the peripheral blood remains an issue of ongoing controversy (Giralt et al, 2011). Repetitive applications of the granulocyte colony-stimulating factor (G-CSF) alone can effectively mobilize peripheral CD34+ cells, whereas the combination of G-CSF with chemotherapy is usually associated with a more potent recruitment of CD34+ cells from the bone marrow niche. The additional administration of the expensive stem cell mobilizing compound plerixafor represents a rescue strategy for patients failing such mobilization strategies.

Based on the considerations above, the combined use of chemotherapy and G-CSF is a widely used concept. While high-dose cyclophosphamide with G-CSF is commonly given for chemotherapy mobilization, the administration of a single dose of non-myelosuppressive chemotherapy with vinorelbine $\left(35 \mathrm{mg} / \mathrm{m}^{2}\right)$ together with G-CSF started on day 4 is the standard mobilization regimen in Switzerland since more than a decade (Bargetzi et al, 2003; Heizmann et al, 2009; Samaras et al, 2015; Schmid et al, 2015). Its obvious advantages compared to cyclophosphamide treatment comprise a highly predictable stem cell collection 
at day 8 , the entirely ambulatory concept, and the lack of infectious and toxic complications notoriously following cyclophosphamide mobilization (Bargetzi et al, 2003; Heizmann et al, 2009; Samaras et al, 2015; Schmid et al, 2015).

With the predominant use of bortezomib during induction treatment and with chemotherapy-induced polyneuropathy (CIPN) as its major and often limiting side effect, the subsequent use of vinorelbine for mobilization has become increasingly problematic because of its added neurotoxicity (Argyriou et al, 2008; Carlson et al, 2011; Delforge et al, 2010; Keller et al, 2015; Koeppen et al, 2014; Mohty et al, 2010; Richardson et al, 2006; Swain et al, 2008). Clinically significant induction of novel - as well as aggravation of bortezomib induced - CIPN following mobilization treatment with a single dose of vinorelbine in myeloma patients has recently been reported by our group (Keller et al, 2015). These facts identified a need for an alternative non-neurotoxic mobilization chemotherapy, while preserving the advantages of a non-myelosuppressive strategy.

Gemcitabine has been previously used for stem cell mobilization as a part of polychemotherapy regimens in Hodgkin lymphoma patients (Suyani et al, 2011). However, its use as monochemotherapy for mobilization has not been reported so far. In this study, we investigated the safety and effectiveness of gemcitabine together with G-CSF for the mobilization of autologous stem cells in myeloma patients after bortezomib/dexamethasonebased induction treatment. 


\section{PATIENTS AND METHODS}

\section{Patients and study design}

This is a single-center prospective study analyzing all consecutive myeloma patients undergoing first-line consolidation treatment with high-dose melphalan chemotherapy (HDCT) and autologous stem cell transplantation (ASCT) between 03/2012 and 02/2013. Patients must have been treated with a bortezomib/dexamethasone-based induction regimen, the age neded to be below 71 years, and a minimum renal function with a kreatinin clearance of $40 \mathrm{ml} / \mathrm{min}$ and neutrophils above $1.0 \mathrm{G} / \mathrm{L}$ were required. Clinical characteristics and treatment details of the patient cohort are depicted in Table 1. The local ethics committee of Berne, Switzerland with decision \#143/2014 approved this study.

Data sources were medical records of the patients. Neuropathy was assessed by two independent investigators, with T.P. having been one of them for all study patients. In addition, a standardized questionnaire was filled out by all study patients. The questionnaire assessed signs and treatment of neuropathy as well as the subjective disease burden of chemotherapy induced polyneuropathy; it also helped to verify the information retrieved from the medical records. A $100 \%$ response rate was achieved.

\section{Chemomobilization and autologous stem cell transplantation}

Gemcitabine was administered to all patients as a 30 minute infusion at $1250 \mathrm{mg} / \mathrm{m}^{2}$ on day 1 , and filgrastim (G-CSF) was given subcutaneously at a dose of $1 \mathrm{Mio} \mathrm{U} / \mathrm{kg} /$ day divided into two daily doses. G-CSF was started on day 4 and continued until (and including) the day of stem cell collection. Apheresis was triggered at the first day with more than 15'000 CD34+ cells $/ \mathrm{ml}$ in the peripheral blood. $2 \times 10^{6} \mathrm{CD} 34+$ cells $/ \mathrm{kg}$ was the minimum collection requirement, and we aimed to collect between $3-5 \times 10^{6} \mathrm{CD} 34+$ cells/kg per transplant, with usually two transplants being planned. Cell processing procedures followed local standards. Patients received single-day high-dose chemotherapy with melphalan administered 
intravenously at a dose of $200 \mathrm{mg} / \mathrm{m}^{2}$, with peripheral stem cell transplantation at the following day.

\section{Definitions}

The two primary objectives of the study were safety and effectiveness of gemcitabine mobilization treatment. We studied CIPN during induction, mobilization, high-dose and maintenance treatment. We assessed incidence, severity, localization, and specific treatment. CIPN was defined as gemcitabine-induced, when patients presented novel or increased symptoms within two weeks after its administration. CIPN during bortezomibbased induction treatment was identified when it occurred between the first bortezomib administration and up to 30 days after the last dose. CIPN was assessed according to the modified version of the National Cancer Institute Common Toxicity Criteria for Adverse Events (NCl-CTCAE; version 4.03). We used the following categories: general sensory neuropathy (paresthesia, dysesthesia, hypesthesia, hyperesthesia, hyporeflexia, hypalgesia, and decreased temperature sensation); neuropathic pain; general motoric neuropathy (muscle weakness); fasciculation (including tremor and spasm); and ataxia. We also investigated the need for specific analgetic CIPN medication as well as modification or interruption of myeloma specific treatment in order to control CIPN symptoms.

\section{Statistical analysis}

We applied descriptive statistics to calculate variables. We summarized the number of observations, median and range for continuous variables, and we calculated the number and percentage of patients in each category for categorical data. Nominal variables were compared with Fisher exact tests. We used non-parametric Mann-Whitney-U tests for continuous variables. The response rates were defined according to the IMWG criteria. OS was the time from transplantat until the date of death from any cause. PFS was the time from transplantat to first progression, relapse or death whichever occurred first. Patients without 
progression or death were censored at their last follow-up. We designed time-to-event estimates (PFS, OS) according to the Kaplan-Meier method using the log-rank (Mantel-Cox) test. Data cut-off date was April 1, 2015. All p-values were two-sided, and a $P$-value of less than .05 was considered statistically significant. We performed all analyses using the GraphPadPrism software (Version 6.0b, GraphPad Software, Inc, San Diego, CA). 


\section{RESULTS}

\section{Patients}

Between 03/2012 and 02/2013, 24 consecutive myeloma patients at the University Hospital in Bern, Switzerland received bortezomib/dexamethasone-based first-line induction treament and subsequent chemomobilization with gemcitabine and G-CSF as per protocol. The patient characteristics at diagnosis and additional information on the chemotherapy regimens are listed in Table 1. The median age at diagnosis of the patients in our cohort was 61 years (range 52-70 years). Patients mostly had IgG subtype (50\%), whereas the type of light chains involved and ISS stages were equally distributed. FISH analyses was available in 17 patients $(71 \%)$. All 24 patients received an induction treatment with bortezomib and dexamethasone (VD). In addition, two patients further received cyclophosphamide (VCD), two patients had doxorubicin (PAD), two patients were also treated with thalidomide (VTD), and two patients received lenalidomide (VRD), respectively.

\section{Stem cell mobilization and transplantation}

Detailed information on mobilization, stem cell collection and transplantation are summarized in Table 2. All patients received gemcitabine at the planned dose of $1250 \mathrm{mg} / \mathrm{m} 2$ at day 1 . None of the patients experienced neutropenia $<0.5 \mathrm{G} / \mathrm{L}$ or thrombocytopenia $<50 \mathrm{G} / \mathrm{L}$ following gemcitabine treatment. No bleeding complications and no febrile episodes requiring antibiotic treatment occurred. Two patients developed edema and weight gain requiring diuretic treatment. Ten of the 24 patients were hospitalized during the stem cell mobilization process, with all hospitalizations related to the application of a central venous catheter line for stem cell harvest, with a median hospitalization duration of two days, ranging from two to four days. In 19 patients (79\%), a single day of apheresis was sufficient to obtain the minimum number of $>2 \times 10^{6} \mathrm{CD} 34+$ cells $/ \mathrm{kg}$, whereas five patients $(21 \%)$ needed two days of stem cell collection. Apheresis was initiated after a median of 8 days (range 8 to 10 days) 
after mobilization with gemcitabine. The total median duration of apheresis was 285 minutes, with a range from 70 to 420 minutes. The median final collection of CD34+ cells was $9.51 \mathrm{x}$ $10^{6}$ cells $/ \mathrm{kg}$, with a range from 4.95 to 19.2 . We found that more than $10 \times 10^{6} \mathrm{CD} 34+$ cells $/ \mathrm{kg}$ b.w. were collected in $54 \%$ of the patients. Finally, none of the patients improved the remission status following gemcitabine treatment.

All patients in this study underwent subsequent high-dose chemotherapy with $200 \mathrm{mg} / \mathrm{m} 2$ melphalan, with peripheral stem cell transplantation at the following day. The patients received a median of $3.4 \times 10^{6} \mathrm{CD} 34+$ cells $/ \mathrm{kg}$ (range 2.0 to 5.4). All patients had successful engraftment. The median time to recovery was 11 days (range 11 to 13 days) for neutrophils (ANC > $0.5 \mathrm{G} / \mathrm{l}$ ), 13 days (range 9 to 21 days) for platelets $>20 \times 10^{9} / \mathrm{l}$, and 20 days (range 15 to 40 days) for platelets $>100 \times 10^{9} /$. Maintenance treatment after ASCT was given in 15 patients (63\%), with lenalidomide in all these patients.

\section{Chemotherapy induced polyneuropathy (CIPN)}

The incidence of CIPN during induction and mobilization treatment is summarized in Table 3. In one patient (5\%), polyneuropathy was pre-existing, most likely due to diabetes mellitus in this patient. Evaluation of clinical assessment together with the patient questionnaire indicated that any signs of clinical manifestation of CIPN during bortezomib-based induction treatment occurred in 21 of 24 myeloma patients $(88 \%)$. We found that the differences observed in the total incidence of CIPN as documented by the treating physicians in their medical charts compared to the data retrieved from individual questionnaires were not significant $(P=.45)$.

Symptoms of CIPN were first reported after a mean of 6.88 weeks of bortezomib treatment. As depicted in Table 4, CIPN affected patients predominantly reported sensory symptoms $(68 \%)$, with grade $\mathrm{I} / \mathrm{II}$ in $48 \%$ and grade III/IV in $20 \%$. Motoric symptoms were documented in 7 patients (28\%), all being grade I or II. Ataxia was identified in two patients (8\%). Standard medication given for neuropathic pain involved pregabalin, gabapentin and 
opioids. Finally, four patients $(16 \%)$ of the patients needed bortezomib dose reduction, prolongation of treatment interval or even interruption of therapy as a consequence of the occurrence of bortezomib-induced CIPN. In two patients (8\%), CIPN resulted in the premature discontinuation of bortezomib treatment. However, none of the patients in this study received a second line of chemotherapy, for whatever reason, before mobilization treatment.

Noteworthy, we observed only one patient (4\%) with worsening of bortezomibinduced sensory CIPN (from grade I to II) during and following mobilization treatment with gemcitabine. Also, a single patient $(4 \%)$ reported worsening of bortezomib-induced sensory CIPN (from grade I to II) following high-dose chemotherapy. During lenalidomide maintenance treatment, two patients (8\%) had worsening of CIPN (one patient from grade I to II, and one patient from grade II to III) as summarized in Table 4.

Repetitive follow-up information on the course of CIPN was available for all patients. Symptoms of CIPN resolved in $14 \%$ of all patients $(n=3)$ until the day 100 assessment after HDCT. In additional 9 (41\%) patients, symptoms gradually improved over time with a median time to disappearance of 5 months (range 4 to 9 months). However, $18 \%$ of the patients $(n=4)$ only had a partial improvement of CIPN, and $27 \%$ of the patients $(n=6)$ considered CIPN still present and a "major problem". Patients described a "very high burden" due to CIPN in $23 \%$, and a "high burden" in another $23 \%$. For $45 \%$ of the patients, CIPN was "tolerable and modest", whereas only 9\% considered it "harmless" (data not shown).

\section{Outcome}

Information on outcome is limited by the small number of study patients. Consequently, we observed no significant differences in response rates at mobilization and 100 days after ASCT when comparing patients with and without CIPN before ASCT. Eight of all 24 study patients so far had a relapse after ASCT, with the median relapse-free survival being not yet reached after a median follow-up of 31 months. The relapse-free survival two years after 
ASCT was $72 \%$. Figure $1 \mathrm{~A}$ depicts the relapse-free survival (RFS) of the entire study cohort, and Figure 1B indicates the overall survival (OS). Two patients died so far, after 10 and 13 months, in both cases due to myeloma progression. Again, the median survival of the entire study cohort was not yet reached, and the median overall survival after two years was $92 \%$. 


\section{DISCUSSION}

Bortezomib based regimens for first-line induction treatment have improved remission and survival rates in myeloma patients and have become standard of care (Richardson et al, 2003; Sonneveld et al, 2013). However, chemotherapy-induced polyneuropathy (CIPN) is a major and often limiting side effect of bortezomib (Argyriou et al, 2008; Delforge et al, 2010; Keller et al, 2015; Koeppen et al, 2014; Mohty et al, 2010; Richardson et al, 2006). In our study cohort, $88 \%$ of myeloma patients treated with subcutaneous bortezomib developed clinical signs of neuropathy of any grade which led in $16 \%$ to prolongation of treatment intervals or discontinuation of bortezomib treatment. The majority of the patients had sensory deficits which is consistent with previous reports on bortezomib inducing a dose-related peripheral, mainly sensory polyneuropathy with accompanying neuropathic pain (Argyriou et al, 2008; Delforge et al, 2010; Keller et al, 2015; Koeppen et al, 2014; Mohty et al, 2010; Richardson et al, 2006). Thus, optimized concepts for the prevention and treatment of bortezomib induced CIPN are obviously essential for myeloma patients, and such strategies involve subcutaneous application, the once weekly administration, and timely discontinuation at early signs of neuropathy to enable reversibility of symtoms (Argyriou et al, 2008; Cavaletti et al, 2010; Stubblefield et al, 2009).

Bortezomib associated CIPN is significantly affecting the quality of life of myeloma patients. The majority (63\%) of myeloma patients affected by CIPN in our study considered the burden of CIPN as "high" or "very high", and more than half of the patients with CIPN failed to completely recover from CIPN, with $31 \%$ reporting unchanged persisting CIPN after completion of HDCT treatment.

Based on these considerations, we evaluated an alternative chemomobilization approach after bortezomib induction. Traditionally, the standard strategy in Switzerland to mobilize peripheral autologous stem cells in myeloma patients is a single-dose of $35 \mathrm{mg} / \mathrm{m} 2$ vinorelbine, with G-CSF stimulation initiated four days later (Bargetzi et al, 2003; Heizmann et al, 2009; Samaras et al, 2015; Schmid et al, 2015). This non-myelosuppressive concept 
allows a highly reliable and efficient stem cell collection at day 8 . This concept has been challenged in the last years with the predominant use of bortezomib during induction treatment and with bortezomib induced polyneuropathy (CIPN) as its major side effect. The vinca-alkaloid vinorelbine is mediating additional neurotoxicity (Capasso et al, 2012; Galano et al, 2011; Lobert et al, 1996), involving hypoesthesia, hyporeflexia, paresthesia and pain, but also motoric or autonomic axons can be dammaged, which is similar to the neurotoxic profile of bortezomib (Capasso et al, 2012; Galano et al, 2011; Lobert et al, 1996). In fact, we previously reported that a single dose of vinorelbine can significantly aggravate bortezomib induced CIPN - or induce first manifestation of CIPN - in bortezomib pretreated myeloma patients (Keller et al, 2015). These observations formed the basis of our study to evaluate an alternative chemomobilization approach while preserving the advantages of a nonmyelosuppressive strategy.

Gemcitabine is a promising candidate for chemomobilization. It has been studied so far as a component of a polychemotherapy mobilization strategy in relapsed Hodgkin lymphoma patients and has been considered both safe and effective (Suyani et al, 2011). However, it has not been used so far as monochemotherapy for mobilization of autologous stem cells. We found that a single dose of $1250 \mathrm{mg} / \mathrm{m} 2$ gemcitabine - together with G-CSF stimulation started at day 4 after gemcitabine - was effective to allow the collection of autologous stem cells in all 24 study patients. Consequently, all patients proceeded to subsequent high-dose chemotherapy treatment and enjoyed timely hematologic recovery and no unexpected infectious or toxic complications. Importantly, we did not observe significant aggravation of bortezomib-induced CIPN - or first occurrence of CIPN - in bortezomib-pretreated myeloma patients following the administration of gemcitabine. These observations suggest that gemcitabine can safely replace vinorelbine for chemomobilization of autologous stem cells in bortezomib-pretreated myeloma patients.

High-dose cyclophosphamide chemotherapy with G-CSF represents the most commonly used chemomobilization regimen. Our data suggest that the combination of GCSF with a single dose of non-myelosuppressive chemotherapy with gemcitabine compares 
favorably to cyclophosphamide mobilization because of its reliable and predictable collection rate at day 8 , the strictly ambulatory setting, and the lack of febrile complications notoriously associated with cyclophosphamide mobilization.

We undertook considerable efforts to identify CIPN during induction and mobilization chemotherapy, but also during high-dose chemotherapy and lenalidomide maintenance treatment. All patients were clinically monitored for the development and assessment of the severity of CIPN, and patients also reported their observations using a standardized questionnaire. The finding of $88 \%$ of all patients showing signs of CIPN after bortezomib induction treatment in this small study appears very high compared to other larger series, Thus, a by chance effect due to the small sample size may have contributed to this high incidence. However, our study points to the possibility that CIPN may remain unrecognized by both treating physicians and patients unaware of the variety of CIPN symptoms.

We observed one patient with aggravation of bortezomib-induced CIPN (from grade I to II) after gemcitabine, one patient after high-dose melphalan chemotherapy, and two patients under lenalidomide maintenance treatment. These observations underline the concept that gemcitabine mobilization, high-dose melphalan and lenalidomide maintenance are not neurotoxic myeloma treatments, and the rare observation of novel neuropathy in bortezomib-pretreated patients suggests the possibility of other mechanisms. Recently, late onset of previously not overt bortezomib induced polyneuropathy was observed, emerging mainly during or shortly after peripheral blood stem cell (PBSC) collection (Tacchetti et al, 2014). A coasting phenomenon of bortezomib was suggested rather than an effect of compounds used between bortezomib-based induction treatment and PBSC collection (Tacchetti et al, 2014). Possibly, such late occurrence of bortezomib toxicity may have been involved in the few patients with CIPN occurring after discontinuation of beortezomib treatment.

We identified a slow recovery rate from bortezomib triggered polyneuropathy. In fact, half of all affected patients continued to suffer from symptoms of disabling CIPN after completion of HDCT treatment. Previous reports suggested that bortezomib (or vinorelbine-) 
induced neuropathy was predominantly reversible after drug discontinuation within two to four months (Argyriou et al, 2008; Koeppen et al, 2014; Mohty et al, 2010). In contrast, improvement of CIPN in our cohort remained incomplete in a significant proportion of patients. In the absence of effective treatment modalities for CIPN, prevention of severe CIPN remains an important goal of induction treatment in myeloma patients (Cavaletti et al, 2010; Mantyh et al, 2006; Stubblefield et al, 2009).

This study was not powered to evaluate the effect of the development of CIPN on response and survival rates. In fact, we observed no differences in response and survival rates between myeloma patients with and without CIPN. However, developing CIPN can affect dosing, duration and the chemotherapy composition of later myeloma treatment thereby affecting response to treatment (Cavaletti et al, 2010; Mantyh et al, 2006; Stubblefield et al, 2009). Consequently, longer follow-up of a larger cohort may be required to ultimately provide answers to these issues. However, our data suggest that gemcitabine represents a promising alternative candidate to replace neurotoxic vinorelbine chemomobilization. Consequently, we initiated a randomized prospective trial comparing vinorelbine and gemcitabine mobilization chemotherapy in myeloma patients, and this trial may ultimately identify a novel role for gemcitabine as a non-neurotoxic and effective stem cell mobilization regimen in myeloma patients. 


\section{ACKNOWLEDGEMENTS}

We wish to thank Marion Bleckmann, Barbara Muster and Irene Briner for help with stem cell data collection, Myriam Legros for providing CD34+ data, and Anke Klingenberg-Rettich and Doris Jaeggi for help with data collection on clinical outcome.

\section{CONTRIBUTIONS}

Performed research, analyzed data and wrote the paper (BUM);

performed research, read and approved the final version of the manuscript (SK);

contributed vital material, read and approved the final version of the manuscript (BMT);

analyzed data, read and approved the final version of the manuscript (KS);

contributed vital material, read and approved the final version of the manuscript (DR);

contributed vital material, read and approved the final version of the manuscript (DB);

contributed vital material, read and approved the final version of the manuscript (TE);

designed research, analyzed data and wrote the paper (TP).

\section{FUNDINGS}

This work was supported by a grant from the Bernische Stiftung für Klinische Krebsforschung (to TP), from the Krebsliga Bern (to TP), and from the EMPIRIS Foundation/Ursula-HechtFonds (to TP).

\section{CONFLICT OF INTEREST}

The authors declare no conflict of interest. 


\section{REFERENCES}

Argyriou AA, Iconomou G, Kalofonos HP (2008) Bortezomib-induced peripheral neuropathy in multiple myeloma: a comprehensive review of the literature. Blood 112: 1 - 11.

Bargetzi MJ, Passweg J, Baertschi E, Schoenenberger A, Gwerder C, Tichelli A, Burger J, Mingrone W, Herrmann R, Gratwohl A, Wernli M (2003) Mobilization of peripheral blood progenitor cells with vinorelbine and granulocyte colony-stimulating factor in multiple myeloma patients is reliable and cost effective. Bone Marrow Transplant 31: 99 - 103.

Blade J, Rosinol L, Sureda A, Ribera JM, Mediavilla J, Garcia-Larana J, Mateos MV, Palomera L, Fernandez-Calvo J, Marti JM, Giraldo P, Carbonell F, Callis M, Trujillo J, Gardella S, Moro MJ, Barez A, Soler A, Font L, Fontanillas M, San MJ (2005) High-dose therapy intensification compared with continued standard chemotherapy in multiple myeloma patients responding to the initial chemotherapy: long-term results from a prospective randomized trial from the Spanish cooperative group PETHEMA. Blood 106: 3755 - 3759.

Capasso A (2012) Vinorelbine in cancer therapy. Current Drug Targets 13: 1065 - 1071.

Carlson K, Ocean AJ (2011) Peripheral neuropathy associatd with microtubule-targeting agents: occurence and management approach. Clinical Breast Cancer 11: 73 - 81.

Cavaletti G, Jakubowiak AJ (2010) Peripheral neuropathy during bortezomib treatment of multiple myeloma: a review of recent studies. Leuk Lymphoma 51: 1178 - 1187.

Delforge M, Bladé J, Dimopoulos MA, Facon T, Kropff M, Ludwig H, Palumbo A, Van Damme P, San-iguel JF, Sonneveld P (2010) Treatment-related peripheral neuropathy in multiple myeloma: the challenge continues. Lancet Oncol 11: 1086 - 1095.

Fermand JP, Katsahian S, Divine M, Leblond V, Dreyfus F, Macro M, Arnulf B, Royer B, Mariette X, Pertuiset E, Belanger C, Janvier M, Chevret S, Brouet JC, Ravaud P (2005) High-dose therapy and autologous blood stem-cell transplantation compared with conventional treatment in myeloma patients aged 55 to 65 years: long-term results of a randomized control trial from the Group Myeloma Autogreffe. J Clin Oncol 23: 9227 - 9233.

Galano G, Caputo M, Tecce MF, Capasso A (2011) Efficacy and Tolerability of Vinorelbine in the Cancer Therapy. Current Drug Safety 6: 185 - 193.

Giralt S, Stadtmauer EA, Harousseau JL, Palumbo A, Bensinger W, Comenzo RL, Kumar S, Munshi NC, Dispenzieri A, Kyle R, Merlini G, San Miguel J, Ludwig H, Hajek R, Jagannath S, 
Blade J, Lonial S, Dimopoulos MA, Einsele H, Barlogie B, Anderson KC, Gertz M, Attal M, Tosi P, Sonneveld P, Boccadoro M, Morgan G, Sezer O, Mateos MV, Cavo M, Joshua D, Turesson I, Chen W, Shimizu K, Powles R, Richardson PG, Niesvizky R, Rajkumar SV, Durie BG (2009) International myeloma working group (IMWG) consensus statement and guidelines regarding the current status of stem cell collection and high-dose therapy for multiple myeloma and the role of plerixafor (AMD 3100). Leukemia 23: 1904 - 1912.

Harousseau JL, Moreau P (2009) Autologous hematopoietic stem-cell transplantation for multiple myeloma. N Engl J Med 360: 2645 - 2654.

Heizmann M, O'Meara AC, Moosmann PR, Heijnen IA, Zuberbühler M, Fernandez P, Burger J, Huber A, Wernli M, Bargetzi MJ (2009) Efficient mobilization of PBSC with vinorelbine/GCSF in patients with malignant lymphoma. Bone Marrow Transplant 44: 75 - 79.

Keller S, Seipel K, Novak U, Mueller BU, Taleghani BM, Leibundgut K, Pabst T (2015) Neurotoxicity of stem cell mobilization chemotherapy with vinorelbine in myeloma patients after bortezomib treatment. Leuk Res accepted.

Koeppen S (2014) Treatment of Multiple Myeloma: Thalidomide-, bortezomib-, and lenalidomide-induced peripheral neuropathy. Oncol Res Treat 37: 506 - 513.

Lobert S, Vulevic B, Correia JJ (1996) Interaction of vinca alkaloids with tubulin: a comparison of vinblastin, vincristine, and vinorelbine. Biochemistry 31: 5374 - 5380.

Ludwig H, Beksac M, Bladé J, Boccadoro M, Cavenagh J, Cavo M, Dimopoulos M, Drach J, Einsele H, Facon T, Goldschmidt H, Harousseau JL, Hess U, Ketterer N, Kropff M, Mendeleeva L, Morgan G, Palumbo A, Plesner T, San Miguel J, Shpilberg O, Sondergeld P, Sonneveld P, Zweegman S (2010) Current Multiple Myeloma Treatment Strategies with Novel Agents: A European Perspective. The Oncologist 15: 6 - 25.

Mantyh PW (2006) Cancer pain and its impact on diagnosis, survival and quality of life. Nature Rev Neuroscience 7: 797 - 809.

Mohty B, El-Cheikh J, Yakoub-Agha I, Moreau P, Harousseau JL, Mohy M (2010) Peripheral neuropathy and new treatments for multiple myeloma: background and practical recommendations. Haematologica 95: 311 - 319.

Rajkumar SV (2011) Multiple myeloma: 2012 update on diagnosis, risk-stratification, and management. American J Hemat 87: 79 - 88. 
Richardson PG, Barlogie B, Berenson J, Singhai S, Jagannath S, Irwin D, Rajkumar SV, Srkalovic G, Alsina M, Alexanian R, Siegel D, Orlowski RZ, Kuter D, Limentani SA, Lee S, Hideshima T, Esseltine DL, Kauffman M, Adams J, Schenkeln DP, Anderson KC (2003) A phase 2 study of bortezomib in relapsed, refractory myeloma. N Engl J Med 348: 2609 2617.

Richardson PG, Briemberg H, Jagannath S, Wen PY, Barlogie B, Berenson J, Singhai S, Siegel DS, Irwin D, Schuster M, Srkalovic G, Alexanian R, Rajkumar SV, Limentani S, Alsina M, Orlowski RZ, Najarian K, Esseltine D, Anderson KC, Amato AA (2006) Frequency, characteristics, and reversibility of peripheral neuropathy during treatment of advanced multiple myeloma with bortezomib. J Clin Oncol 24: 3113 - 3120.

Samaras P, Pfrommer S, Seifert B, Petrausch U, Mischo A, Schmidt A, Bargetzi M (2015) Efficacy of vinorelbine plus G-CSF for CD34+ hematopoietic progenitor cell mobilization in patients with multiple myeloma. Biol Blood Marrow Transplant 21: 74 - 80.

Schmid A, Friess D, Mansouri Taleghani B, Keller P, Mueller BU, Baerlocher GM, Leibundgut K, Pabst T (2015) Role of plerixafor in autologous stem cell mobilization with vinorelbine chemotherapy and granulocyte-colony stimulating factor in patients with myeloma: a phase II study (PAV-trial). Leuk Lymphoma 56: 608-614.

Sonneveld P, Goldschmidt H, Rosinol L, Bladé J, Lahuerta JJ, Cavo M, Tacchetti P, Zamagni E, Attal M, Lokhorst HM, Desai A, Cakana A, Liu K, van de Velde H, Eseltine D, Moreau P (2013) Bortezomib-based versus nonbortezomib-based induction treatment before autologous stem-cell transplantation in patients with previously untreated multiple myeloma: a meta-analysis of phase III randomized, controlled trials. J Clin Oncol 31: 3279 - 3288.

Stubblefield MD, Burstein HJ, Burton AW, Custodio CM, Deng GE, Ho M, Junck L, Stephen Morris G, Paice JA, Tummala S, Von Roenn JH (2009) NCCN Task force report: management of neuropathy in cancer. J Natl Compr Canc Netw 7: 1 - 26.

Suyani E, Sucak GT, Aki SZ, Yegin ZA, Özkurt ZN, Yagci M (2011) Gemcitabine and vinorelbine combination is effective in both as a salvage and mobilization regimen in relapsed or refractory Hodgkin lymphoma prior to ASCT. Ann Hematol 90: 658 - 691.

Swain SM, Arezzo JC (2008) Neuropathy associated with microtubule inhibitors: diagnosis, incidence, and management. Clin Adv Hematol Oncol 6: 455 - 467.

Tacchetti P, Terragna C, Galli M, Zamagni E, Petrucci MT, Pezzi A, Montefusco V, Martello M, Tosi P, Baldini L, Pecatori J, Ruggieri M, Pantani L, Lazzaro A, Elice F, Rocchi S, 
Gozzetti A, Palumbo A, Cavaletti G, Cavo M (2014) Bortezomib- and thalidomide-induced peripheral neuropathy in multiple myeloma: clinical and molecular analyses of a phase 3 study. American J Hemat 89: 1085-1091.

1

2

3

4

5

6

7

8

9

10

11

12

13

14

15

16

17

18

19

20

21

22

23

24

25

26

27

28

29

30

31

32

33

34

35

36

37

38

39

40

41

42

43

44

45

46

47

48

49

50

51

52

53

54

55

56

57

58

59

60 


\section{TITLES AND LEGENDS TO FIGURES}

Figure 1: A) Kaplan-Meier curves are depicted for the relapse-free survival (RFS) and B) for the overall survival (OS) of the entire study cohort. 
Table 2: Mobilization and transplantation.

\begin{tabular}{|c|c|}
\hline $\begin{array}{l}\text { gemcitabine chemotherapy + G- } \\
\text { CSF, } n(\%)\end{array}$ & $24(100)$ \\
\hline one day of apheresis & $19(79)$ \\
\hline two days of apheresis & $5(21)$ \\
\hline 1st apheresis at day 8 & $16(67)$ \\
\hline 1st apheresis at day 9 & $7(29)$ \\
\hline 1st apheresis at day 10 & $1(4)$ \\
\hline median (mean) & $8(8.38 \pm 0.57)$ \\
\hline duration of apheresis, mean, minutes & $269.71 \pm 91.27$ \\
\hline median, minutes (range) & $285(70-420)$ \\
\hline mean blood volume processed, liters & 26.2 \\
\hline median, liters (range) & $25.3(13.5-33.9)$ \\
\hline leukocytes at apheresis ${ }^{a}$, mean $(G / l)$ & $33.80 \pm 12.94$ \\
\hline median (range) & $34.4(7.90-55.6)$ \\
\hline \multicolumn{2}{|l|}{ peripheral CD34-Wert at apheresis ${ }^{a}$} \\
\hline mean $\left(\times 10^{9} / \mathrm{ml} \mathrm{PB}\right)$ & $56.3 \pm 38.1$ \\
\hline median, x 106 / ml PB (range) & $50.5(4.4-122.4)$ \\
\hline \multicolumn{2}{|l|}{$\%$ CD34 leukocytes at apheresis ${ }^{a}$} \\
\hline mean & $0.19 \pm 0.32$ \\
\hline median (range) & $0.14(0.02-0.68)$ \\
\hline \multicolumn{2}{|l|}{ total collected CD34+x $10^{6} / \mathrm{kg} \mathrm{b} .{ }^{d}{ }^{d}$} \\
\hline mean & $10.09 \pm 6.61$ \\
\hline median (range) & $9.51(4.95-19.2)$ \\
\hline $\begin{array}{l}\text { patients with }>5 \times 10^{6} / \mathrm{kg} \text { CD34+ } \\
\text { cells after the } 1^{\text {st }} \text { day of apheresis }\end{array}$ & $23(96)$ \\
\hline \multicolumn{2}{|l|}{ transfused CD $34+x 10^{6} / \mathrm{kg} \mathrm{b.w.}{ }^{\mathrm{d}}$} \\
\hline mean & $3.51 \pm 0.97$ \\
\hline median (range) & $3.4(2.0-5.4)$ \\
\hline \multicolumn{2}{|l|}{ first day of $A N C^{b}>0,5 \times 109 / L-n(\%)$} \\
\hline day 11 & $14(58)$ \\
\hline day 12 & $9(38)$ \\
\hline day 13 & $1(4)$ \\
\hline mean & $11.46 \pm 0.58$ \\
\hline median (range) & $11(11-13)$ \\
\hline \multicolumn{2}{|l|}{ first day of PIts ${ }^{c}>20 \times 109 / L-n(\%)$} \\
\hline days $10-12$ & $5(21)$ \\
\hline day 13 & $8(33)$ \\
\hline days $14-15$ & $9(38)$ \\
\hline >day 15 & $2(8)$ \\
\hline mean & $13.63 \pm 2.27$ \\
\hline median (range) & $13(9-21)$ \\
\hline \multicolumn{2}{|l|}{ first day of Plts ${ }^{c}>100 \times 109 / L-n(\%)$} \\
\hline$\leq$ day 20 & $13(54)$ \\
\hline days $20-30$ & $8(33)$ \\
\hline$>$ day 30 & $3(12)$ \\
\hline mean & $22.04 \pm 5.88$ \\
\hline median (range) & $20(15-40)$ \\
\hline
\end{tabular}

\footnotetext{
${ }^{a}$ at the first day of apheresis; ${ }^{b}$ ANC: absolute neutrophil count; ${ }^{c}$ Plts; platelets; in the absence for transfusions in the previous three days; ${ }^{\mathrm{d}}$ b.w.: body weight.
} 